\title{
Enseñar morfología en Educación Secundaria de un modo inductivo. El humor como herramienta del análisis morfológico*
}

\section{Teaching Morphology in High School in an Inductive Way. Humor as a tool for morphological analysis}

\author{
María del Carmen Horno-Chéliz \\ Universidad de Zaragoza \\ mhorno@unizar.es \\ ORCID ID: http://orcid.org/0000-0001-9499-4015
}

DOI: $10.17398 / 1988-8430.35 .1 .137$

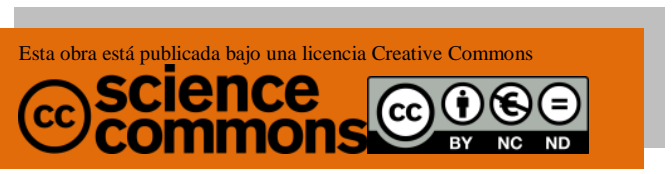

Fecha de recepción: $22 / 04 / 2021$

Fecha de aceptación: 20/09/2021

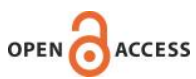

Horno-Chéliz, Ma del C. (2022). Enseñar morfología en Educación Secundaria de un modo inductivo. El humor como herramienta del análisis morfológico. Tejuelo, 35(1), 137-174.

Doi: https://doi.org/10.17398/1988-8430.35.1.137

\footnotetext{
* Este trabajo se ha realizado en el marco del Grupo de Investigación de referencia de la DGA Psylex y el IPH de la Universidad de Zaragoza. Se ha beneficiado del Proyecto de Investigación del Ministerio de Economía y Competitividad CONESSO (FF12017-82460-P) y del Proyecto de investigación del Ministerio de Ciencia e Innovación POSE (PID2019-111198GB-100).
} 
Resumen: El objetivo de este artículo es presentar una serie de ejercicios para enseñar morfología en el aula de secundaria de un modo diferente. Todos ellos se apoyan en juegos de palabras, chistes lingüísticos o ejemplos reales para que sean los estudiantes los que extraigan, a partir de ahí, el comportamiento morfológico de su lengua. El punto de partida es que los procesos morfológicos están presentes en la vida cotidiana de los estudiantes. Son procesos que usamos para crear nuevas palabras, para entender los neologismos, para expresar emociones o para condensar significados a través de la gramática. Con estos ejercicios, se trata de transmitir a los estudiantes que el conocimiento de la lengua radica en su propia reflexión metalingüística y es un conocimiento significativo. Se fomentan competencias básicas como la observación de la realidad, la reflexión y el espíritu crítico. Además, al introducir el humor en el aula, tratamos de crear un clima adecuado para la formación, al mismo tiempo que se fomenta la desautomatización de los procesos lingüísticos.

Palabras clave: morfología; humor; lengua; didáctica; educación.
Abstract: The objective of this article is to present a series of exercises to teach morphology in a different way in high school. All of them rely on word games, linguistic jokes or real examples so that the students are the ones who deduce the morphological behavior of their language. The starting point is that morphological processes are present in the students' daily lives. We use morphology to create new words, to understand neologisms, to express emotions or to condense meanings through grammar. With these exercises, the aim is to convey to students that knowledge of the language lies in their own metalinguistic reflection. Basic competences such as observation of reality, reflection and a critical spirit are promoted. In addition, by introducing humor in the classroom, we try to create a suitable climate for training and promote the de-automation of linguistic processes.

Keywords: morphology; humor; language; teaching; education. 


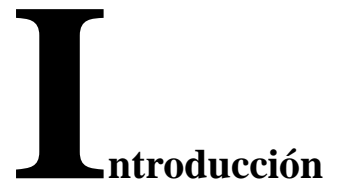

Siguiendo a Bosque y Gallego (2016), el propósito de la clase de lengua en la educación secundaria debe ir más allá del fomento de la lectura y la mejora de las competencias comunicativas de nuestros estudiantes. Sin menospreciar estos objetivos, el aula de lengua debe orientar a los estudiantes no universitarios a observar los hechos linguiísticos, plantearse preguntas, animarse a realizar hipótesis sobre el hecho observado, generalizarlas y comprobarlas en nuevos datos. Al hacerlo, estaremos fomentando el espíritu científico y la certeza de que la lengua es de los hablantes y no de los libros de texto.

Para llevar este objetivo a cabo, pensamos que es imprescindible que la clase de lengua se llene de ejemplos reales problemáticos y no solo de definiciones y ejemplos ad hoc. En concreto, la propuesta que aquí presentamos es utilizar chistes cortos como los que se suelen encontrar en las redes sociales. La razón es doble: por un lado, el humor de estos chistes se basa, precisamente, en el descubrimiento de los mecanismos lingüísticos que de otro modo resultan invisibles, por 
obvios, para el estudiante; por otro lado, porque observar, proponer hipótesis, generalizarlas y comprobarlas son tareas a las que nuestros estudiantes no están acostumbrados y que, por tanto, pueden ocasionar cierto estrés. Si se realizan a partir de materiales de humor, es razonable pensar que dicho efecto se reducirá.

En el presente trabajo se presentarán ejemplos concretos de actividades en los que distintos materiales humorísticos sirven de base para analizar de forma inductiva la estructura y los procesos de formación de las palabras complejas. En concreto, una vez que se haya reflexionado sobre el papel del estudio inductivo y el humor en el aula de lengua (apartado 1) se presentarán ejemplos de actividades para trabajar la morfología. El punto de partida son las funciones de la morfología en nuestra cotidianidad: la creación de nuevas palabras (apartado 2), la comprensión de neologismos (apartado 3), la expresión de la afectividad (apartado 4) y la relación entre la morfología y la gramática (apartado 5). El trabajo finalizará con unas breves conclusiones generales.

\section{1.- Enseñar morfología a través de los juegos de palabras}

Muchos son los problemas de los que adolece la enseñanza de la morfología en el aula no universitaria actual. De todos ellos, en esta ocasión nos vamos a centrar en la descontextualización de los contenidos. La teoría morfológica se presenta como un conjunto de unidades y procesos ajenos a la vida cotidiana del estudiante. Los libros de texto hablan de palabras derivadas, afijos, siglas o compuestos como si toda esa serie de elementos no tuviera nada que ver con la realidad de los hablantes. Sin embargo, la capacidad del lenguaje es probablemente la facultad más importante que tienen los humanos. Al menos, es la habilidad que más ejercen a lo largo del día (todas las actividades se acompañan de actividad lingüística) y, además, es una constante en las situaciones más significativas para nuestra especie (el pensamiento, la consciencia y las relaciones sociales). 
$\mathrm{Ni}$ siquiera las actividades planteadas en los libros de texto suelen ser significativas. En la mayoría de las ocasiones se limitan a pedirle al estudiante que reconozca palabras derivadas y las clasifique de forma adecuada, como si estuviera tratando con objetos ajenos a su realidad. El máximo intento que se reconoce de intentar vincular la morfología con la realidad del alumno consiste en pedirle que identifique y clasifique palabras de un material real (un cartel, un texto, un poema). Sin embargo, estas actividades están lejos de ser significativas. Fundamentalmente, porque no existe ninguna razón para identificar y clasificar palabras. El estudiante reconoce en estos ejercicios la lógica escolástica de aprender algo descontextualizado y ejercitarse hasta que lo domina. La pregunta de ¿para qué sirve la morfología? sigue teniendo así la misma triste respuesta: para aprobar el examen de lengua.

Más allá de sus efectos desmotivadores, esta forma de presentar y ejercitar la morfología tiene como consecuencia que los estudiantes continúen viendo los asuntos gramaticales en general y los morfológicos en particular como algo ajeno a ellos mismos. Estamos ante lo que podríamos denominar El Mito de la Gramática, por el cual las unidades y los procesos gramaticales dependen de los gramáticos y de los libros de texto más que del propio cerebro de los hablantes. Como si lo que estudian en las clases de lengua no tuviera ninguna relación con lo que hacen, de manera inconsciente, cada vez que producen o comprenden enunciados lingüísticos.

El objetivo más importante de las clases de gramática (y, por tanto, de las de morfología) ha de ser que los estudiantes entiendan que todo lo que en ellas se aprende tiene que ver con el proceso de codificación y descodificación de los mensajes lingüísticos; que no se trata de un conjunto de ejercicios escolásticos cuya misión es mantenerlos ocupados, sino que consiste en tratar de describir y explicar de la manera más adecuada posible los procesos que se dan constantemente en interacción y que permiten que se produzca el intercambio linguiístico. 
Con este propósito en mente, el presente trabajo va a vincular las unidades y procesos morfológicos con la función que estos tienen en las actividades lingüísticas. Hablaremos de derivación, composición, acronimia o flexión, pero no de un modo descontextualizado, sino en tanto en cuanto nos permite crear nuevas palabras, entender neologismos con los que nunca antes nos habíamos topado o gramaticalizar significados. Los estudiantes aprenderán a reconocer todos estos procesos al mismo tiempo que aprenden para qué son útiles o por qué los utilizamos.

Antes de pasar a desarrollar las actividades, debemos detenernos en dos aspectos fundamentales de nuestra propuesta: una docencia centrada en la presentación inductiva de los contenidos (epígrafe 1.1) y en la que el humor esté presente (epígrafe 1.2).

\section{1.- El estudio inductivo en el aula}

El estudio inductivo parte de la observación de los datos y, a partir de ellos, saca conclusiones y generaliza los resultados. En la clase de lengua, consiste en partir de enunciados reales y dar la oportunidad a los estudiantes de que saquen ellos las conclusiones. Se trata, por tanto, de hacer justo lo contrario de lo que se suele hacer. Habitualmente es el profesor/a quien explica cómo son las cosas y después (a veces) muestra algunos ejemplos que evidencian lo que acaba de explicar. Una clase de morfología podría comenzar hablando, por ejemplo, de las partes de la palabra compleja (raíz, prefijos, sufijos) e inmediatamente después mostrar un ejemplo (im-pensa-ble). La propuesta de estudio inductivo implica hacer el camino inverso. Se le permite al estudiante que reflexione sobre la relación entre impensable, pensar, incalculable, calcular, calculable y otras palabras que presenten el mismo prefijo, la misma raíz y el mismo sufijo y se le permite que saque sus propias conclusiones a través de la manipulación, la contrastación y la generalización. La propuesta teórica (en este caso, las partes de la palabra compleja) será la conclusión de la clase y no el inicio; el objetivo al que queremos que lleguen los alumnos/as y no el punto de partida que se les ofrece sin reflexión. 
Las ventajas de partir de los datos lingüísticos y llegar con ellos a la propuesta teórica son numerosas. En primer lugar, con esta forma de proceder en el aula se supera la tendencia a poner etiquetas y se dedica el tiempo de clase a profundizar en el comportamiento lingüístico de los elementos. Tal y como advierte Bosque (2018), en ocasiones parece que el análisis lingüístico se reduce a un problema terminológico, de tal modo que cuando somos capaces de darle un nombre a una determinada unidad o proceso ya poco más podemos hacer con ello. Sin embargo, como en todas las demás ciencias, asignar un nombre no puede ser sino uno de los objetivos del análisis y ni siquiera el más importante. Mucho más interesante que la mera denominación es el análisis de sus propiedades, de cuáles son sus límites y sus posibilidades. Llevar el estudio inductivo al aula implica provocar las actitudes (de reflexión, espíritu crítico, descripción, generalización, formulación de hipótesis) que toda ciencia debería fomentar.

Por otra parte, dado que los datos empíricos de los que partimos son enunciados de la lengua materna de gran parte de nuestros estudiantes, con este modo de actuar nos beneficiamos de su competencia como hablantes. Así, estamos ayudando a romper El Mito de la Gramática del que hablábamos antes. De cómo funciona la gramática no hay nadie que sepa más que un hablante nativo. La labor del profesor/a es guiarle en la reflexión metalingüística, aportando las herramientas adecuadas para ello y respetando su juicio como hablante competente. De este modo, el estudiante no solo aprende morfología, sino también que el conocimiento que tiene sobre su propia lengua es pertinente y que tiene el derecho y la obligación de reflexionar sobre su capacidad linguística. Actuando de este modo promoveremos, en último término, la posibilidad de que se conviertan en ciudadanos acostumbrados a reflexionar sobre cómo usan la lengua ellos mismos y los demás.

Obviamente, este paso al estudio inductivo en el aula de lengua implica, necesariamente, un cambio de mentalidad en el docente. En primer lugar, debe estar dispuesto a escuchar lo que el estudiante, como 
hablante competente, tenga que decir. Debe considerar como pertinentes sus juicios de valor y ser capaz de guiarlos en la reflexión para que lleguen a buen puerto. Además, es necesario que esté dispuesto a que los estudiantes le realicen preguntas para las que quizá no tenga respuesta. Ante esto es importante remarcar dos cosas. En primer lugar, que si un docente consigue que los estudiantes realicen ese tipo de preguntas, puede estar seguro de que está haciendo muy bien su trabajo. Uno de los principales objetivos de la docencia es fomentar la curiosidad y la capacidad de hacerse preguntas ante la realidad. En segundo lugar, que lo esperable es que el profesor/a no tenga todas las respuestas. El conocimiento científico de la naturaleza no es algo terminado y finito. El docente de lengua, como cualquier otro, debe transmitir a sus estudiantes la necesidad de hacerse preguntas y las herramientas y los medios para acercarse a las respuestas. Solo el conocimiento religioso cabe en un libro. El científico está en constante elaboración. Está bien que los estudiantes lo sepan.

\section{2.- El humor en el aula de lengua}

El valor pedagógico del humor está fuera de toda duda (Fernández Solís, 2003). En primer lugar, crea el clima adecuado para el aprendizaje, pues fomenta la motivación y ayuda a desdramatizar los errores. El tipo de relación que se crea entre el docente y los estudiantes es muy beneficioso, dado que ayuda a relajar tensiones y a estar más abiertos al conocimiento. Las emociones positivas que se generan son beneficiosas para los procesos de enseñanza-aprendizaje y para la salud en general (Fredickson 2004, Fernández-Poncela, 2019). Además, utilizar el sentido del humor dentro del aula ayuda a crear un efecto burbuja, por el que los problemas y el pesimismo del mundo cotidiano no entran dentro de clase. Los estudiantes pueden olvidarse, por un rato, de todo aquello que les estresa y les preocupa y centrarse en el aquí y el ahora. Dejar entrar el humor al aula también es beneficioso para el docente, siempre que sepa controlar al grupo y no permita que se despisten con los juegos y las bromas. Es posible que el profesor/a que es capaz de bromear en clase sin perder por ello el liderazgo sienta un mayor apego a su trabajo y su salud mental mejore. 
No obstante, usar el humor como recurso pedagógico va más allá de crear un buen ambiente en clase. En concreto, el uso de juegos de palabras o chistes linguiísticos (que será la propuesta que haremos aquí) promueve la reflexión, desautomatiza el conocimiento morfológico del estudiante y favorece el metanálisis. Para entender esto de manera adecuada debemos partir de que el procesamiento lingüístico es una actividad mental que realizamos de un modo automático (como respirar o hablar), de tal modo que no somos conscientes de lo que hacemos. Los denominados chistes lingüísticos tienden a incidir en estos procesos automatizados y permiten la reflexión lingüística. De este modo, si permitimos que nuestros estudiantes partan de un juego de palabras o un chiste para comenzar la reflexión metalingüística, gran parte del camino se habrá recorrido solo.

\section{2.- La creación de palabras nuevas}

Tal y como decíamos en el apartado anterior, es importante presentar los procesos morfológicos en relación con la vida cotidiana de nuestros estudiantes como hablantes competentes de una lengua. Por ello, antes de pasar a describir unidades o procesos, lo primero que se debe presentar son las funciones que la morfología tiene en los procesos lingüísticos. En qué momentos de la vida de los hablantes está especialmente presente y cómo funciona. Desde esta perspectiva, podemos comenzar con una de las funciones más obvias de los procesos morfológicos: los seres humanos somos capaces de crear nuevas palabras.

La pregunta de inicio sería, por tanto: ¿para qué creamos palabras? Dejemos que sean los estudiantes los que reflexionen sobre cuáles son los contextos en los que necesitamos formar nuevas palabras. A veces será un simple olvido: no recordamos la expresión lingüística adecuada y creamos otra para expresar lo que queremos decir (como cuando un niño pequeño dice: ;Ya tengo descansamiento! para expresar que ya está descansado). Otras veces creamos palabras para lograr un efecto humorístico, como cuando llamamos estudiador (en lugar de 
estudiante) al amigo que lleva 15 años estudiando Derecho. Sin embargo, en otras ocasiones se trata de procesos mucho más serios, con consecuencias más importantes para nuestra vida. Estamos hablando de aquellos momentos en los que tenemos que poner nombre a una empresa o a un producto que vamos a comercializar, los denominados procesos de naming (Aranda Gutiérrez, 2011). En estas ocasiones ya no se trata de un proceso tan automático ni tan baladí. Por el contrario, se tratará de un proceso reflexivo y consciente que tendrá importantes consecuencias en el éxito o fracaso de nuestro negocio. No obstante, en todos esos casos, tanto cuando lo hacemos de manera inocente como cuando se trata de un relevante asunto de marketing, los procesos morfológicos que están detrás son los mismos. Y en clase de lengua podemos estudiarlos.

Otra pregunta relevante antes de pasar a analizar los procesos morfológicos propiamente dichos sería la siguiente: ¿qué dice la creación de palabras sobre cómo somos los humanos? Porque, hasta donde sabemos, los seres humanos somos los únicos que ponemos nombres a todo para poder entender la realidad. Los procesos de creación de palabras nos presentan como seres creativos, capaces de encontrar patrones en las palabras que usamos y formar con ellos nuevas palabras (abastecer, desabastecer, desabastecimiento; cansar, descansar, *descansamiento; luchar, luchador; estudiar, *estudiador). Pero también nos dicen cómo funciona nuestra cognición. Los seres humanos accedemos al conocimiento a través de los nombres que damos. De este modo, ser capaces de crear nuevas palabras a veces implica la capacidad de crear nuevos conceptos, nuevas formas de ver la realidad. Una palabra como juernes, más allá del proceso de acronimia que veremos después, es interesante por lo que implica desde un punto de vista social. Con ella designamos los jueves en los que hay fiestas como si fueran viernes. Crear una palabra como juernes, por tanto, dice mucho sobre nuestra manera de vivir, de entender el mundo. Y reflexionar sobre ello también debería formar parte del currículum de la morfología. 


\section{1.- La derivación}

Como decíamos antes, en los libros de texto de secundaria y bachillerato, la explicación de los procesos derivativos se suele reducir a identificar las bases, las raíces y los afijos derivativos o a crear palabras derivadas a partir de raíces o sufijos. En los ejercicios siguientes mostramos cómo se puede reflexionar sobre los procesos derivativos de un modo más profundo, incidiendo en la competencia del estudiante y en su capacidad metalingüística.

\section{Imagen 1}

Ejercicio de morfología derivativa que explota la polisemia del sufijo -ista

Ejercicio 1.

Considere el siguiente juego de palabras y conteste a las preguntas:

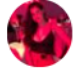

Andrea

@ noculpesalkarma

No quiero ser alarmista pero mi padre tiene una empresa de alarmas y seguridad y la voy a heredar.

a) ¿Qué dos interpretaciones tiene aquí la palabra alarmista?

b) Relacione cada una de las interpretaciones con otras palabras similares y extraiga su comportamiento gramatical: ¿a qué categoría pertenece? ¿con qué palabras se puede combinar y con cuáles no?

Fuente: elaboración propia

Para resolver este ejercicio, tenemos que recurrir a las dos acepciones de alarmista. La habitual (la que interpretamos todos en un primer momento) es un adjetivo calificativo que tiene como significado 'que hace cundir noticias alarmantes'. Se vincula a otros adjetivos calificativos formados a partir de un sustantivo y el sufijo -ista como juerguista, machista, etc. Como buen adjetivo calificativo admite variar en grado y ser cuantificado (muy alarmista, algo machista, tan bromista como, más bromista que, etc.). Sin embargo, el chiste se basa en interpretar alarmista como un sustantivo del campo semántico de las profesiones, como futbolista, regatista, flautista, violinista, etc. En esta acepción, la cuantificación y el grado no se aplican (?muy flautista, ?más violinista que, etc.). 
Como vemos, lo interesante de este ejercicio es que son los estudiantes los que deben ofrecer los dos posibles significados de una palabra derivada $\mathrm{y}$, a partir de ahí, desarrollar un análisis metalingüístico que nos llevará a observar, desde un punto de vista general, las diferencias que muestran sustantivos y adjetivos $\mathrm{y}$, desde un punto de vista más particular, el doble valor de un sufijo como -ista. Podemos acabar el ejercicio recurriendo al Diccionario de la Lengua Española y comprobando que el sufijo -ista tiene recogidas estas dos acepciones $^{1}$ :

\section{Imagen 2}

Significados del sufijo -ista según el Diccionario de la Real Academia Española

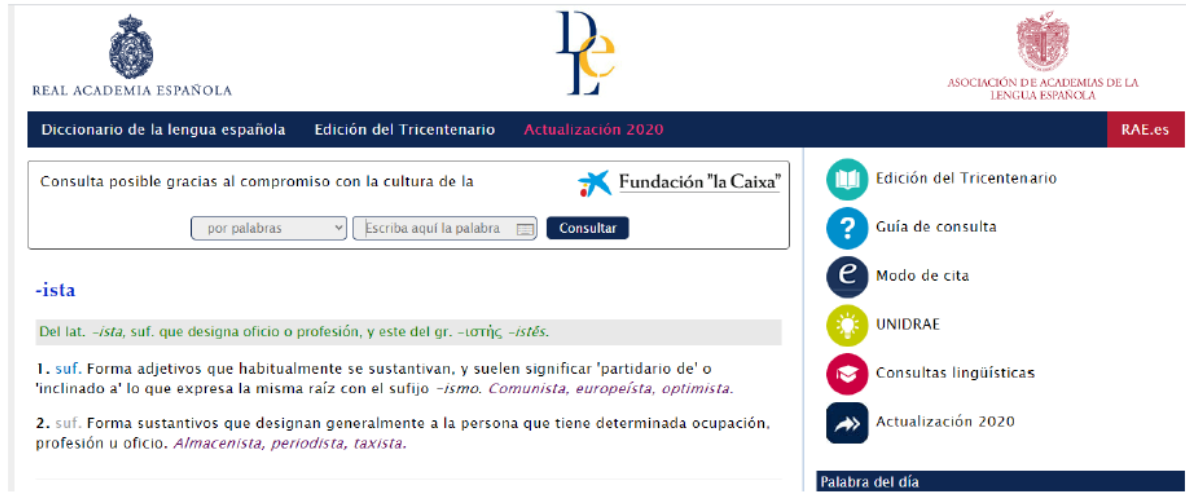

Fuente: Significados del sufijo -ista según el Diccionario de la Real Academia Española

${ }^{1}$ Para un análisis más detallado de este sufijo, v. Santiago Lacuesta y Bustos Gisbert, 1999: 4570-4573. 


\section{Imagen 3}

Ejercicio de morfología derivativa que explota las restricciones combinatorias del sufijo -mente

\section{Ejercicio 2.}

Observe el siguiente anuncio. ¿Qué opinión le merece el adverbio cuadradamente? ¿Qué características debe tener un adjetivo para que forme adverbios en -mente?

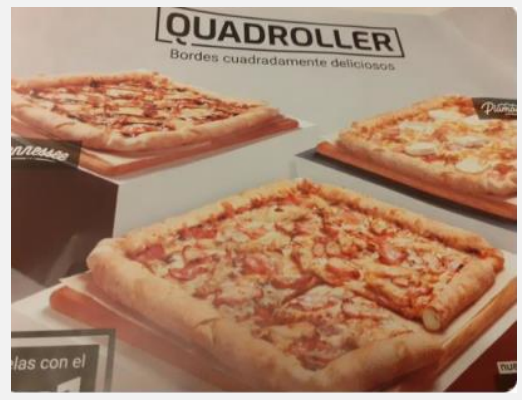

Fuente: elaboración propia

En esta ocasión, le pedimos a nuestros estudiantes que hagan listas de adverbios formados a partir de un adjetivo más el sufijo-mente bien formados (como estupendamente, maravillosamente, realmente...) y mal formados (como *cuadradamente, *españolamente, *rubiamente...). El ejercicio consiste en que comparen ambas listas y que hagan hipótesis sobre qué es lo que diferencia a unos de otros. La reflexión se puede complicar añadiendo los ejemplos de Varela (1992), en los que determinados participios o adjetivos (interrumpido, repetible, mejorable) no admiten la formación del adverbio en -mente, mientras que sus derivados con prefijación negativa sí la permiten (*interrumpidamente pero ininterrumpidamente, *repetiblemente pero irrepetiblemente, *mejorablemente pero inmejorablemente). En esta ocasión, el objetivo no es llegar a una respuesta a la pregunta (quizá esto excede los objetivos de un aula de lengua no universitaria), sino fomentar la reflexión, la curiosidad y el espíritu crítico (desechando hipótesis erróneas), etc. 


\section{Imagen 4}

Ejercicio de morfología derivativa que explota la alternancia de la base verbal rendir(se)

\section{Ejercicio 3.}

Considere el siguiente chiste lingüístico. ¿Sobre qué verbo está formada la palabra rendimiento? ¿Sobre qué verbo considera el chiste que está formada?

Recoja parejas de verbos similares y observe sobre cuál de ellos puede operar el sufijo -miento

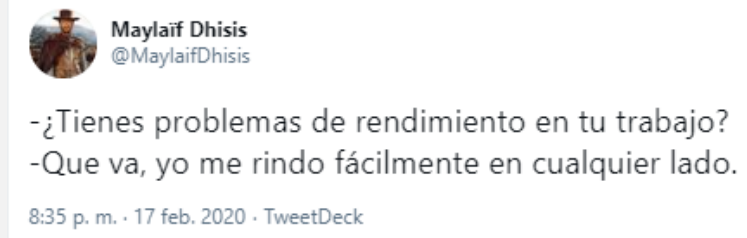

Fuente: elaboración propia

Este tercer ejercicio busca que los estudiantes reparen en las parejas de verbos con y sin pronombre reflexivo, como en rendirrendirse. Es interesante que vean que estos dos verbos tienen significados distintos (no vinculados) y el sufijo -miento se aplica al verbo sin pronombre. Sin embargo, otros verbos, como hundirhundirse, abrasar-abrasarse sí tienen un significado relacionado y el sufijo puede relacionarse con ambos. De nuevo aquí el objetivo no es una propuesta teórica sobre el sufijo -miento. Lo que se busca es despertar la curiosidad de los estudiantes, empoderarles como hablantes competentes y hacerles comprender que el modo en el que está limitada la gramática, como todo en ciencia, es complejo y todavía falta investigación al respecto ${ }^{2}$.

\section{2.- La composición y la acronimia}

En general, los procesos de composición se suelen presentar en los libros de texto como la unión de dos o más palabras para formar una nueva palabra. A continuación, se les suele decir que los compuestos

${ }^{2}$ Para un análisis del sufijo -miento, v. Santiago Lacuesta y Bustos Gisbert, 1999, pp. 4574-4580. 
pueden ser propios (como pelirrojo) o sintagmáticos (como hombre lobo). Una pregunta que podría (debería) hacerse un estudiante al leer esto es en qué medida un compuesto es diferente a un sintagma. Para fomentar que reflexionen sobre esta cuestión, se presenta el siguiente ejercicio:

\section{Imagen 5}

Ejercicio de morfología derivativa que profundiza en la diferencia entre compuesto y sintagma

Ejercicio 4.

Considere el siguiente chiste lingüístico. ¿Qué dos interpretaciones tiene aquí la palabra malherido? ¿Cuál de las dos coincide con el significado del compuesto?

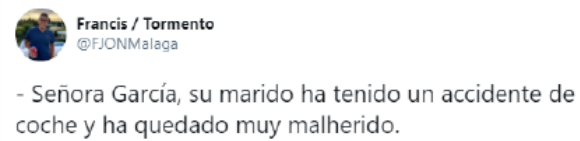

- Madre mía, ni herirse sabe ...

12:20 p. m. 18 ago. 2019 - Twitter for iphone

Fuente: elaboración propia

Si los estudiantes buscan en el diccionario la palabra malherido verán que se les remite a malherir, que es un compuesto que significa 'herir de gravedad'. La intepretación habitual del participio remite, por tanto, a este significado lexicalizado (fijo) del compuesto (Varela y Martín García, 1999, p. 5035). Sin embargo, la capacidad de los hablantes de interpretar un compuesto como un elemento composicional queda intacta. De ahí que se pueda entender el chiste. Este ejercicio es, así, un excelente medio para que los estudiantes vean de forma clara la diferencia entre un sintagma (en el que los significados de las partes se combinan) y un compuesto (en el que el significado está fosilizado, lexicalizado o fijo).

Por otra parte, frente a la composición, que consistía en unir varias palabras, los procesos de acronimia mezclan material fonológico de varias palabras para formar una nueva. Hasta hace poco, en español, la acronimia no era muy habitual. Una vez presentados los mecanismos de la composición y la acronimia en clase, podemos usar el siguiente ejercicio para reflexionar sobre las diferencias al respecto entre el inglés 
y el español. De hecho, se puede realizar una actividad transversal entre ambas asignaturas y trabajar cómo se resuelve en español determinadas palabras formadas como acrónimos (blending) en inglés:

\section{Imagen 6}

Ejercicio de morfología derivativa que profundiza en la diferencia entre composición y acronimia a partir de la comparación entre el español y el inglés

\section{Ejercicio 5.}

Observe esta comparación entre la formación de palabras en inglés y en español. ¿Cómo se llama y en qué consiste cada uno de estos procesos? ¿Puede buscar más ejemplos en inglés y en español que sigan este patrón? ¿Recuerda algún compuesto en inglés? ¿Y algún acrónimo en español? (actividad transversal)

Modesto García @ @modesto_garcia.10 ene.

Ingleses creando palabras:

Breakfast + Lunch: Brunch

Españoles creando palabras:

Merienda + Cena: Merienda-cena

Mostrar este hilo

Fuente: elaboración propia

Tal y como afirmaba Casado Velarde (1999), la acronimia en español es un fenómeno relativamente reciente al que se le ha concedido todavía escasa atención. Sin embargo, su incidencia en la conversación coloquial es cada vez mayor, por lo que resulta muy adecuado reflexionar sobre ello en el aula de secundaria: por una parte, se presenta un problema que conecta con la forma de hablar de los estudiantes; por otra, se trata de un asunto poco estudiado que requiere de nuevas investigaciones. Hablar sobre ello implica presentar el estudio de la morfología como una investigación en proceso sobre datos reales, de tal modo que los estudiantes pueden sentirse como un elemento activo y no un simple receptor. 


\section{Imagen 7}

Ejercicio de morfología derivativa que profundiza en la diferencia entre composición y acronimia a partir del sustantivo apartahotel

Ejercicio 6.

Considere el siguiente chiste. ¿Cómo se ha formado la palabra apartahotel y cómo piensa el del chiste que se ha formado?

Fuente: elaboración propia

En esta ocasión el objetivo es que el estudiante reflexione sobre la naturaleza de apartahotel como acrónimo: Un apartahotel es un apartamento con características de hotel (ciertos servicios, como la comida o la limpieza). Desde el punto de vista morfológico, supone un acrónimo porque implica la pérdida de material fonológico de una de las palabras.

Este ejercicio puede propiciar una reflexión sobre el uso de los acrónimos en la actualidad. Nuestros estudiantes, por influencia del inglés, usan mucho más este proceso de formación de palabras que las generaciones más adultas, por lo que no tendrán problema de encontrar ejemplos en su día a día (juernes, veroño, viejoven).

Sin embargo, el chiste está basado en la interpretación de apartahotel como compuesto, formado por verbo (apartar) más nombre (hotel). Este tipo de compuestos formados por verbo más sustantivo, donde el nombre se interpreta como el complemento directo del elemento verbal, son los más comunes en español, pues presentan un proceso de alta vitalidad en nuestra lengua (Val Álvaro, 1999, p. 4788). Sería interesante una reflexión al respecto y que recogieran compuestos de este tipo (sacacorchos, limpiamuebles, abrebotellas...). 


\section{3.- Entendemos palabras: raíz y afijos. Familias léxicas}

Más allá de la capacidad de los seres humanos de crear nuevas palabras, gracias a la morfología somos capaces de entender el significado de nuevas palabras. De este modo, la primera vez que nos encontramos con una palabra compleja es posible que podamos adivinar su significado si la podemos relacionar con otras palabras que presentan las mismas raíces o los mismos afijos. Volviendo a los ejemplos que poníamos en el apartado anterior, si trato de conseguir un efecto humorístico con una palabra como estudiador necesito que mis interlocutores reconozcan su significado. Al igual que en el proceso de creación, para interpretar este neologismo se recurrirá a patrones de formación de palabras (luchar: luchador, estudiar: estudiador). Con esta reflexión podemos contestar ya a la pregunta de para qué sirve entender nuevas palabras usando la morfología: gracias a esta capacidad, emisor y receptor pueden estar interconectados, sincronizados. Tiene sentido que el hablante sea capaz de crear nuevas palabras porque el oyente las puede entender. En caso contrario, no serviría de nada.

En otro orden de cosas, esta capacidad doble de crear y entender nuevas palabras conlleva una importante ventaja económica, pues hace innecesaria la memorización de formas nuevas para denominar nuevos conceptos. De este modo, la morfología se presenta como un recurso básico para no tener que listar un elevado número de formas independientes en nuestro lexicón mental. Es más, gracias a las relaciones que se establecen entre las distintas palabras de una familia léxica, el diccionario mental, que está formado a partir de un conjunto de redes léxicas, se cohesiona de un modo más intenso. La morfología permite relacionar con más facilidad unas palabras con otras.

\section{1.- Raíces y elementos compositivos}

En este proceso de comprender palabras nuevas, las raíces tienen un papel predominante. En el siguiente ejercicio se permite reflexionar sobre su naturaleza. 


\section{Imagen 8}

Ejercicio de morfología derivativa que profundiza en la naturaleza de la Familia Lingüística

\section{Ejercicio 7.}

Considere el siguiente cartel tomado de un tweet de @pablocardelino. ¿Constituyen una familia linguística las palabras leche, lechuga y lechones? ¿Por qué se ha escrito de esta manera?

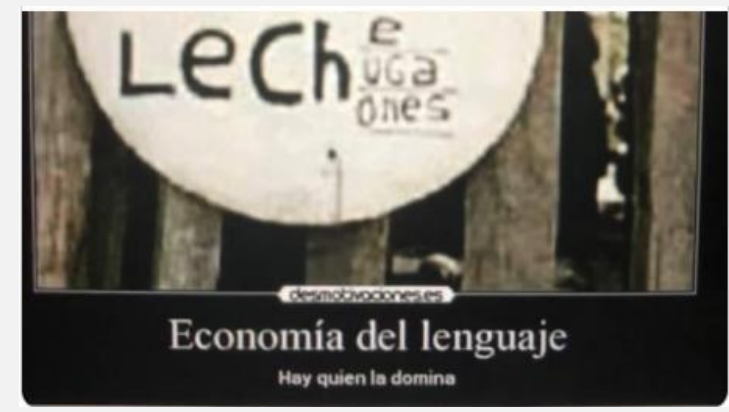

Fuente: elaboración propia

Para que distintas palabras con material fonológico coincidente se puedan considerar una familia de palabras es imprescindible que dicho material fonológico implique un significado único. De este modo, palabras como madre, maternidad, maternal constituyen una familia de palabras no solo porque comparten este material fonológico $(\mathrm{madr} / \mathrm{t})$, sino porque comparten un significado relacionado con la progenitora femenina ${ }^{3}$. En este caso, por tanto, lo que tienen que decidir los estudiantes es si leche, lechuga y lechones comparten, además del material fonológico (lech-), algún tipo de información semántica asociada.

Probablemente la respuesta de los estudiantes sea que no, porque, si bien lechones sí se puede relacionar con leche, la palabra lechuga la considerarán probablemente independiente. De este modo, en el lexicón mental de nuestros estudiantes (que es el que nos interesa, como hablantes que son), estas tres palabras no formarían una familia lingüística.

${ }_{3}^{3}$ Para el concepto de raíz, revísese el trabajo de Pena (1999, pp. 4314-4318). 
Este ejemplo es especialmente interesante porque en realidad la palabra lechuga viene del latín LACTUCA, palabra derivada de LAC, LACTIS ('leche'). De este modo, se puede reflexionar sobre la naturaleza de las familias lingüísticas, que tiene que ver más con la conciencia del hablante que con la etimología en sí. Dicho de otro modo, a pesar de que lechuga y leche tengan un origen común ${ }^{4}$, el hecho de que los hablantes actualmente no reconozcan la relación semántica hace que no debamos considerarlas de la misma familia lingüística. En realidad, si uno no conoce el significado de lechuga, su relación etimológica con leche no le será de ayuda. Convenimos, por tanto, con Martín García y Varela (2012) y con Gil Laforga (2020) en que el análisis morfológico en el aula debe ser sincrónico.

Pero no solo las raíces ayudan a entender las palabras nuevas con las que tenemos que lidiar en el día a día. También los elementos compositivos nos ayudan a dar un significado adecuado a los neologismos. En el siguiente ejercicio sugerimos reflexionar sobre el poder de estos elementos para la interpretación adecuada de las palabras que no tenemos listadas en nuestro lexicón mental.

\section{Imagen 9}

Ejercicio de morfología derivativa que ayuda a reflexionar sobre los neologismos

\section{Ejercicio 8.}

En el siguiente intercambio comunicativo entre un padre y su hija aparece un neologismo. ¿Cómo se ha formado? ¿Con qué otras palabras lo relacionamos para interpretarlo? ¿Qué significado tiene aquí tele-? ¿Con qué finalidad ha creado la palabra el padre?

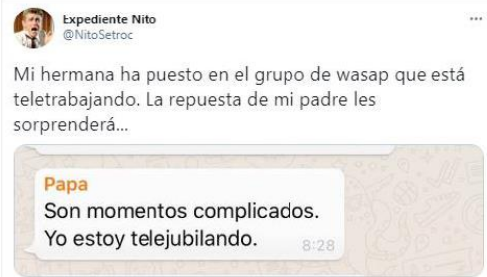

Fuente: elaboración propia

${ }^{4}$ Tal y como comenta uno de los revisores de este artículo, la relación entre lechuga y leche proviene de que, al cortar la lechuga, brote un líquido blanco, muy parecido al de la leche, de los tallos. 
Este ejercicio nos permite reflexionar sobre un elemento compositivo como tele-, tan productivo actualmente debido a la actual situación sanitaria. Sería interesante hacer una lista de palabras con este elemento (televisión, teléfono, teletransportarse, teletrabajar, teleconferencia, telemedicina...). Antes de la pandemia, las palabras formadas con tele- eran fundamentalmente sustantivos ligados a la tecnología. La novedad ahora quizá sea incorporar esta formación neológica a los verbos. La respuesta del padre, en este sentido, tiene algo de crítica al uso abusivo de este elemento. Tal vez se podría relacionar con otros procesos de formación de palabras, como el uso de vídeo (videollamada, videoconferencia, videoconsulta...). La lengua está viva y es permeable a los cambios vitales de la sociedad que la usa.

\section{2.- Prefijos y sufijos}

Cuando tratamos de darle significado a una palabra compleja que desconocemos, los prefijos y los sufijos también nos resultan de ayuda. En el ejercicio siguiente se pone de manifiesto esta capacidad dándole un nuevo sentido a una palabra compleja conocida.

\section{Imagen 10}

Ejercicio de morfología derivativa que explota la ambigüedad de la base nominal de la palabra desahogo

Ejercicio 9.

Considere el siguiente chiste y reflexione sobre el valor del prefijo. ¿Qué significa ahogo? ¿Qué efecto semántico tiene el prefijo sobre esa base léxica?

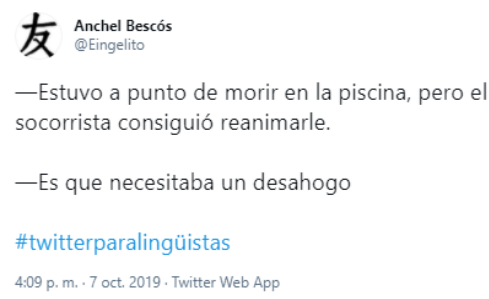

Fuente: elaboración propia 
La palabra ahogo tiene un sentido literal y otro metafórico. Sin embargo, la palabra derivada desahogo solo se ha formado a partir del uso metafórico. De ahí que al forzarla para que se interprete en un sentido literal se genere un efecto humorístico. Los estudiantes pueden buscar en el diccionario otras palabras con el prefijo des- (desabrochar, desabastecer) y comprobar que lo habitual es que se aplique el prefijo a los sentidos literales de la base. La lexicalización de las palabras complejas es un proceso arbitrario.

Otro asunto interesante para reflexionar es el proceso de derivación que utiliza afijos ambiguos. El siguiente ejercicio intenta explotar este fenómeno.

\section{Imagen 11}

Ejercicio de morfología derivativa que explota la ambigüedad del sufijo -ero/a

Ejercicio 10.

Considere el siguiente chiste y reflexione sobre el valor del sufijo. ¿Qué valor aporta ero/a a la base léxica? Haga una lista con palabras derivadas en las que aparezca este sufijo y decida el significado que aporta en cada caso. ¿Existen más casos de ambigüedad como el del ejemplo?

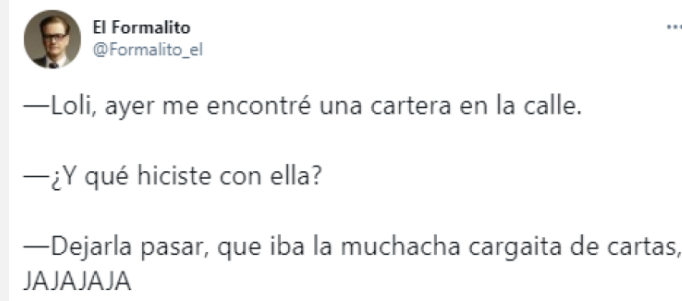

Fuente: elaboración propia

Con este ejercicio esperamos que los estudiantes sean capaces de reconocer, al menos, dos significados del sufijo - ero: el valor locativo ('lugar en el que se guardan las cartas'), como en cenicero, joyero, abrevadero... y el valor agentivo ('persona que trabaja distribuyendo cartas'), como en bombero, panadero, joyero... Es fácil que, al hacer esta lista de nombres derivados con este sufijo, encuentren ejemplos de 
ambigüedad. En la pequeña lista presentada aquí tenemos joyero ('lugar en el que se guardan las joyas' o 'persona que trabaja con joyas') ${ }^{5}$.

Es interesante reflexionar aquí, por otro lado, sobre la importancia del contexto para asignar el valor adecuado a las palabras derivadas con más de un significado. En el chiste del ejercicio 10, la clave está en el verbo encontrar, que presupone un evento inesperado y que suele seleccionar, bien sustantivos de cosa ('encontrar algo'), como en encontrar unas gafas, un bolso, etc., bien nombres propios de persona ('encontrar a alguien conocido'), como en encontrar a Juan, al profesor de Pedrito, etc. De este modo, uno de los dos sentidos de la palabra cartera cumple con estas expectativas mucho mejor que el otro. De ahí que ni siquiera seamos conscientes de la ambigüedad de esta palabra y de ahí el efecto humorístico de este ejemplo.

Por último, es también interesante mostrar cómo los afijos no siempre tienen el significado que les atribuimos. Para reflexionar sobre este hecho sugerimos el siguiente ejercicio:

\section{Imagen 12}

Ejercicio de morfología derivativa que reflexiona sobre el valor aspectual de los sufijos -izar y-ecer

\section{Ejercicio 11.}

Reflexione sobre la siguiente pregunta que plantea Bárbara Marqueta en su twitter. ¿Qué diferencia de significado tienen los sufijos -izar y -ecer? Recopile un conjunto de ejemplos de verbos con uno y otro sufijo y trate de generalizar el significado de ambos afijos. ¿Qué problema representa agonizar?

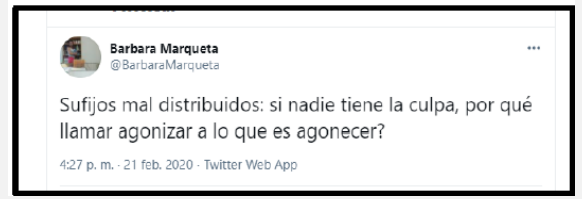

Fuente: elaboración propia

${ }^{5}$ Para un análisis del sufijo - ero, v. Santiago Lacuesta y Bustos Gisbert, 1999, pp. 4555-4560). 
Los estudiantes deberán realizar una lista de verbos con el sufijo izar: hospitalizar, sensibilizar, carbonizar, esclavizar, impermeabilizar... A partir de estos ejemplos se puede ver que este sufijo implica normalmente un contenido causativo ('alguien hace algo de tal modo que otra persona u otra cosa termina en un hospital, más sensible, hecho carbón, hecho esclavo, impermeable, etc.'). Con respecto al sufijo - ecer los estudiantes pueden recoger ejemplos como florecer, enmudecer, envejecer, palidecer, enrojecer... El contenido común de estos verbos es un cambio de estado ('alguien o algo pasa a tener flor, a ser mudo, viejo, pálido, enrojecido...'). Tras esta generalización, la observación del ejercicio cobra sentido: en agonizar, el significado que aporta el sufijo no es el causativo, sino el incoativo.

Por último, es interesante resaltar cómo, en ocasiones, las palabras fosilizan, de tal modo que el significado de los afijos no ayuda a entender el significado de la palabra derivada. Es lo que ocurre con la palabra desfallecer que, tal y como apunta @ complutense en un tweet, no significa 'nacer' (como podría creerse de un análisis morfológico como des-fallecer).

\section{4.- Jugamos con las palabras: apreciativos, acortamientos, abreviaturas}

Al principio de este trabajo decíamos que las palabras nos acompañan en todas nuestras actividades significativas. Hemos visto hasta el momento cómo somos capaces de crear y entender nuevas palabras en momentos de olvido, en situaciones en las que queremos conseguir un efecto de humor o ante la necesidad de nombrar algo nuevo. En este apartado vamos a reflexionar sobre cómo solemos expresar nuestra afectividad a través de las palabras. La morfología nos permite marcar cercanía, cariño, admiración, rechazo... Procesos morfológicos como la sufijación apreciativa o los acortamientos están detrás de esto. 


\section{Imagen 13}

Ejercicio de morfología para reflexionar sobre la función de acortamientos y apreciativos en la comunicación cotidiana

\section{Ejercicio 12.}

Considere las siguientes palabras de la nube. ¿Cuáles de ellas utiliza en su día a día? ¿Cuáles entiende pero no usa? ¿De qué contextos comunicativos son propias?

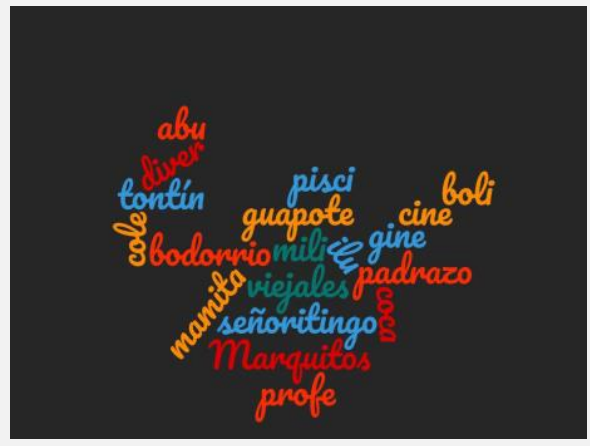

Fuente: elaboración propia

Una vez que se haya reflexionado sobre el uso de estas palabras, es interesante que se profundice en la forma. En primer lugar, distinguiríamos entre acortamientos (pisci, boli, ilu) y apreciativos (tontín, Marquitos, padrazo).

Es importante recalcar que no solo encontramos apreciativos en nombres y adjetivos, sino, por ejemplo, también en adverbios o verbos (prontito, dormitar). En el caso concreto de los adverbios, hay bastante variación geográfica, hasta el punto de que en determinados dialectos (piense en el español de México, por ejemplo) es mucho más habitual que en otros (ahorita, por ejemplo). Sin embargo, algunos adverbios admiten el diminutivo en español estándar, como el del siguiente ejercicio: 


\section{Imagen 14}

Ejercicio de morfología que ayuda a reflexionar sobre las posibilidades combinatorias de los diminutivos

\section{Ejercicio 13.}

Considere la siguiente reflexión: ¿cuántos adverbios aceptan los diminutivos en su variedad dialectal?

¿Quién iba a decir que al ver un diminutivo interpretemos más fácilmente que se trata de un adverbio que de un nombre \#twitterparalingüistas via @antoniombeltran

\section{(1) DexterM @DexterMad · 4 sept. 2019 Definición de "Cerquita"}

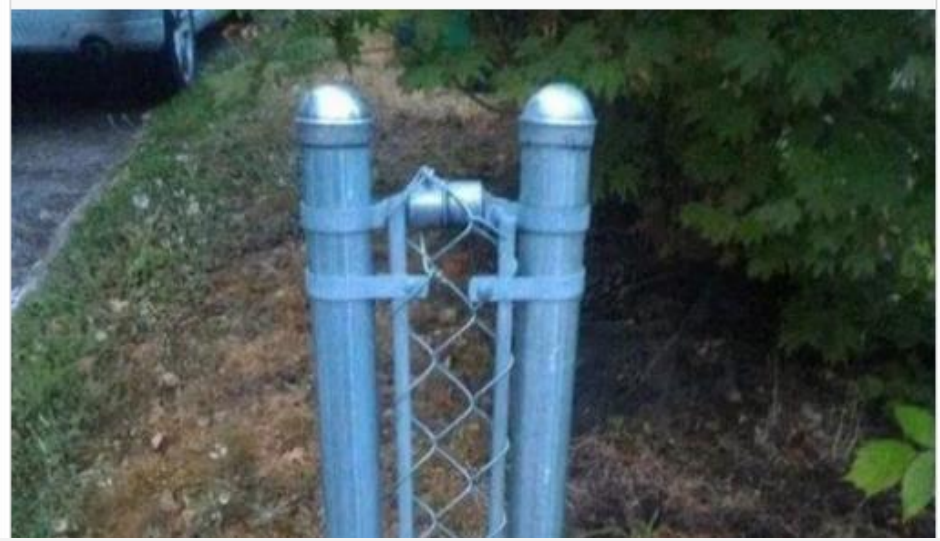

Fuente: elaboración propia

Darse cuenta de que los diminutivos no solo se aplican a sustantivos y adjetivos ayuda a reflexionar sobre el valor de los apreciativos en la lengua. En el siguiente ejercicio se anima a pensar sobre ello: 


\section{Imagen 15}

Ejercicio de morfología que ayuda a reflexionar sobre el significado de los morfemas apreciativos

\section{Ejercicio 14.}

Considere la siguiente reflexión: ¿qué significado aportan los apreciativos en estas descripciones de las fiestas de Nochevieja?

\footnotetext{
Si te quedas en casa usas diminutivos para contarlo:

"Aquí, en casita, con un vinito, cenita, los coleguitas...".

Si sales, usas aumentativos: "Buah, aquí, bailando

temazos, de fiestón, con unos pibonazos que flipas".

¿Amén a esto, hermanos?
}

Fuente: elaboración propia

\section{5.- La gramática y la información morfológica. La flexión}

Una última función de la morfología nos queda por subrayar. Gracias a los procesos morfológicos expresamos en una sola palabra contenidos gramaticales complejos. Así, a través de la morfología flexiva podemos expresar cuándo ha ocurrido algo, cuántas veces, o incluso si realmente ha ocurrido o se trata tan solo de un deseo. Podemos dar información sobre el sexo de nuestro interlocutor, de cuántos objetos estamos hablando, etc. No obstante, este significado que aparece en la morfología flexiva no siempre es tan sencillo como creemos. En los siguientes ejercicios el objetivo es reflexionar sobre ello.

\section{1.- Tiempo y aspecto}

Los verbos en una lengua como el español presentan información de tiempo y aspecto. Normalmente se presenta en clase la distinción entre presente, pasado y futuro relacionada con el momento de emisión del acto de habla y entre imperfecto y perfecto, en virtud de si la acción ha terminado o no. Sin embargo, en las interacciones reales la información que dan los morfemas de tiempo y aspecto es más rica. En 
los ejercicios 15 y 16 se pretende que los estudiantes reflexionen sobre ello.

\section{Imagen 16}

Ejercicio de morfología flexiva que muestra los diferentes valores temporales del presente simple

\section{Ejercicio 15.}

Considere el siguiente chiste. ¿Qué dos valores del presente se están confundiendo aquí? ¿Qué reflexión le merece?

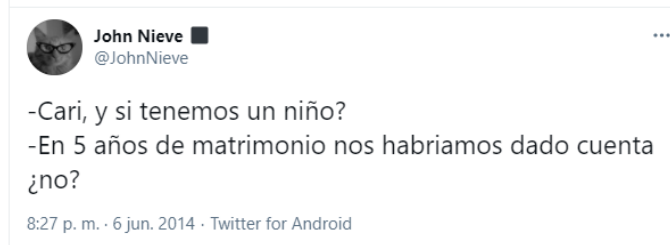

Fuente: elaboración propia

Los estudiantes no tendrán problema de identificar un valor incoativo (de futuro) en el presente del verbo tener. Este valor no es el que se suele vincular al tiempo presente y de ahí el efecto humorístico del chiste. A partir de este ejemplo se les puede pedir que piensen otros ejemplos cotidianos en los que utilizamos el presente simple con este valor incoativo sin necesidad de construcciones sintácticas que ayuden a esta interpretación (del tipo de ¿y si..?). Un ejemplo de este tipo es cuando decimos ¿cenamos? cuando se acerca la hora de preparar la cena o en oraciones afirmativas del tipo Mañana voy al médico.. 


\section{Imagen 17}

Ejercicio de morfología flexiva que muestra los diferentes valores aspectuales del presente simple

\section{Ejercicio 16.}

Considere el siguiente titular. ¿Qué ha entendido el twittero y qué pretendía decir el titular? ¿Está bien expresado, tal y como está? Reflexione sobre ello:

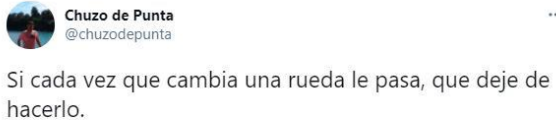
hacerlo.

Un hombre queda atrapado bajo su coche cuando cambia una rueda en Vigo

Fuente: elaboración propia

Este ejemplo es algo más difícil que el anterior y sería mejor utilizarlo únicamente con estudiantes más avanzados (incluso de bachillerato). En él vemos un uso frecuente en la prensa y sobre todo en los titulares de periódico, que usan el presente simple para expresar tiempo pasado. En esta ocasión, al utilizar este uso anómalo del presente dos veces (oración principal y subordinada), acaban provocando un efecto indeseado: la interpretación de que se trata de un evento habitual, de tal modo que siempre que se da el evento subordinado se da el principal. Esto es lo que crea el efecto humorístico subrayado por el twittero. A los estudiantes se les puede pedir que reflexionen sobre este uso del presente en la prensa y que sustituyan el presente por un tiempo y un aspecto más adecuados.

\section{2.- Modo y voz}

Si hay un tipo de información que parece ser ajena por completo a la vida de los estudiantes es la de modo y voz de los verbos en lenguas como el español. Los estudiantes aprenden las formas en indicativo y subjuntivo o en activa y pasiva como un mero ejercicio escolástico que 
poco o nada tiene que ver con sus habilidades comunicativas. Los ejercicios 17 y 18 tratan de compensar esto y animan a los alumnos/as a pensar sobre los efectos comunicativos de estos significados gramaticales.

\section{Imagen 18}

Ejercicio de morfología flexiva que ayuda a reflexionar sobre los valores del modo subjuntivo

\section{Ejercicio 17.}

Considere el siguiente titular, que recoge @JuanjoLara01 en su Twitter. ¿Puede alguien amenazar usando el pluscuamperfecto del subjuntivo? ¿Es una prueba adecuada en un juicio?:

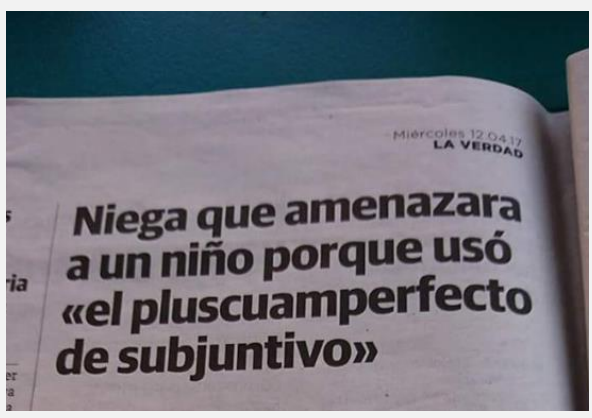

Fuente: elaboración propia

El ejercicio 17 aprovecha un caso real en el que un acusado de amenazas se defiende argumentando que lo que dijo no pudo ser considerado de este modo porque el verbo estaba en pluscuamperfecto de subjuntivo. El ejercicio consiste en reconocer qué forma es esta y reflexionar si podría considerarse o no una amenaza ( $\mathrm{T}$ Te hubiera matado!). ¿Qué necesita un enunciado para ser considerado amenaza? ¿Es imposible usar un verbo en subjuntivo con esta intención comunicativa? ¿Son más amenazantes otros tiempos como el presente o el imperfecto de subjuntivo? 


\section{Imagen 19}

Ejercicio de morfología flexiva que ayuda a reflexionar sobre la importancia de la voz para la interpretación de los enunciados

\section{Ejercicio 18.}

Considere el siguiente titular sobre violencia de género. ¿Qué diferencia hay entre emitir el mensaje en activa o en pasiva? ¿Cómo suele presentarse la violencia de género? Reflexione sobre ello:

$$
\equiv \text { EL PAIS }
$$

ESPAÑA

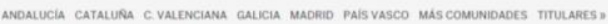

VIOLENCIA DE GENERO :

\section{Asesinada una mujer de 28 años en Tenerife y detenida su pareja}

Fuente: elaboración propia

En esta ocasión, se trata de reflexionar sobre la importancia de la voz en el verbo para la comprensión del enunciado. Habitualmente se dice (porque es verdad) que en español, a diferencia de lo que ocurre en otras lenguas como el inglés, la voz pasiva no se suele utilizar. Sin embargo, es interesante comprobar que en determinados contextos el uso de la voz pasiva es menos infrecuente.

Un ejemplo de esto son los titulares que presentan situaciones de violencia de género. Es interesante que los estudiantes reparen en cómo la información flexiva incide en el modo en el que presentamos los eventos o, incluso, que realicen un pequeño trabajo de investigación en el que comprueben cómo se suele presentar la violencia de género en los periódicos. Tal vez se sorprendan cuando vean que el uso de la pasiva, en este ámbito, es el habitual. Para entender la importancia de esto, se les puede explicar que las oraciones en voz activa focalizan el evento en sí y, en el caso de los sucesos de violencia de género, ponen al agresor en el punto de mira. Por el contrario, las oraciones en pasiva (como las del ejemplo) focalizan la atención en el resultado de los sucesos de violencia $\mathrm{y}$, de algún modo, reducen la carga sobre el agresor. De este modo, la manera en la que se cuenta lo que ha pasado implica en cierto modo el modo en el que se entiende el suceso. El debate está servido. 


\section{3.- Grado}

Del mismo modo que se suele decir que el presente coincide con el tiempo de la enunciación o que la pasiva no se usa en español, también es habitual encontrar en el aula de lengua que el superlativo señala el elemento que presenta en grado máximo la cualidad expresada por el adjetivo. Para reflexionar sobre ello sugerimos el ejercicio siguiente:

\section{Imagen 20}

Ejercicio de morfología flexiva que ayuda a reflexionar sobre los valores del grado superlativo

\section{Ejercicio 19.}

Considere el siguiente titular y conteste a la pregunta que se le realiza a continuación:

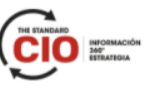

inicio entérate evalúa gestiona transforma apremoe Fintech $f$ v

\section{Seguridad para el trabajo remoto: primera prioridad del $94 \%$ de los CISOs}

¿Qué opinión le merecen expresiones como las siguientes: mi primera prioridad, uno de los puntos más álgidos? Reflexione sobre ello.

Fuente: elaboración propia

Si prioridad es un superlativo, mi primera prioridad debería ser una expresión redundante, carente de sentido. Sin embargo, lo cierto es que todos usamos y entendemos expresiones como esta. Los estudiantes pueden reflexionar sobre la diferencia entre Eres mi prioridad y eres mi primera prioridad y ver cómo se pasa de un superlativo en sentido estricto a un superlativo relativo (en el que hay varios individuos que cumplen la condición hasta el punto de que se pueden jerarquizar). 


\section{4.- Género, número y persona}

\section{Imagen 21}

Ejercicio de morfología flexiva que ayuda a reflexionar sobre la naturaleza del género gramatical

\section{Ejercicio 20.}

Considere el siguiente hilo de Twitter. Un usuario pregunta por el género de covid y la cuenta de @RAEinforma contesta. ¿Qué características tiene el género de los sustantivos no sexuados?

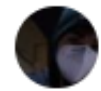

Jhonatan $\equiv @ j h o n y c m m \cdot 10$ mar.

@RAEinforma \#dudaRAE ¿Cuál es la forma más correcta de llamar la enfermedad, el covid o la covid?

Q 1

七

O

实

RAE@@RAEinforma.10 mar.

\#RAEconsultas El acrónimo «COVID-19» que da nombre a la enfermedad se usa normalmente en masculino ( eel COVID-19\%) por influjo del género de «coronavirus» y de otras enfermedades víricas («el zika $w_{f}$ «el ébola»), que toman el nombre del virus que las causa. $1 / 3$

Q.

ใ】

^

RAE

@RAEinforma

En respuesta a @RAEinforma y @jhonycmm

\#RAEconsultas Pero el uso en femenino («la COVID$19 »)$, tal como hace la OMS en sus páginas en español, está justificado por ser «enfermedad» («disease»en inglés) el núcleo del acrónimo («COronaVIrus Disease»). Ambos se consideran válidos. 2/3

11:52 a. m. 10 mar. 2021 - Twitter Web App

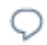

$\uparrow \downarrow$

O

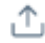

RAE@ @RAEinforma.10 mar.

En respuesta a@RAEinformay @jhonycmm

\#RAEconsultas Su lexicalización como nombre común con la forma «covid»,

Fuente: elaboración propia 
Es muy interesante la reflexión sobre por qué las palabras presentan un género determinado y no otro. Las palabras que remiten a referentes sexuados tienden a asumir el género asociado al sexo del referente (niño vs. niña); en cuanto a las palabras cuyo referente es asexuado, el asunto es más variado. En ocasiones, la explicación remite a la palabra de origen (en muchas ocasiones tendrá que ver con el género de la palabra en latín, por ejemplo). Es interesante, por tanto, ver qué ocurre con palabras de formación nueva o préstamos de lenguas como el inglés, que no marcan género en los sustantivos. En esas ocasiones, no es infrecuente que exista una cierta variabilidad ( $\mathrm{el} / \mathrm{la}$ wifi). Eso es lo que ocurre con el caso del covid. Tal y como explica el responsable de la cuenta de Twitter de la RAE, ambas formas están atestiguadas y responden a motivaciones diferentes. Entender esto implica reconocer el verdadero sentido de la arbitrariedad del género en los sustantivos ${ }^{6}$.

\section{Imagen 22}

Ejercicio de morfología flexiva que ayuda a reflexionar sobre los valores del número gramatical

\section{Ejercicio 21.}

A continuación, presentamos una reflexión hecha por un twittero sobre el valor del plural. ¿Siempre significa más de uno?

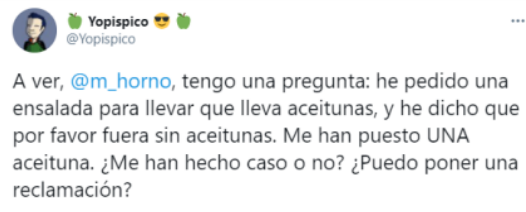

Fuente: elaboración propia

Otro asunto interesante para reflexionar en clase es el significado de la marca de plural. En el ejercicio número 21 se trata de reflexionar sobre el uso del plural en sustantivos. Cuando se usa una expresión negativa (no quiero aceitunas, ensalada sin aceitunas), el plural deja de

${ }^{6}$ Para profundizar sobre la asignación de género, véase Ambadiang (1999: 48464884). 
ser interpretable (de tal modo que el significado de las expresiones anteriores es 'no quiero ninguna aceituna' 'ensalada sin ninguna aceituna'). Lo mismo ocurre con las formas verbales. Cuando decimos llaman a la puerta no queremos decir que estemos seguros de que sea más de una persona la que llama a la puerta (Aijón Oliva, 2020). Reflexionar sobre estos usos no plurales del plural implica profundizar en el uso de los morfemas flexivos, añadir complejidad a lo aprendido años antes y vincular el análisis metalinguiístico de clase al uso real de la lengua.

Por último, es interesante observar que las lenguas no gramaticalizan todos los significados. En concreto, en español, podemos poner el ejemplo de la diferencia entre la primera persona que incluye al oyente (inclusiva) y la que lo excluye (exclusiva). Esta diferencia, presente en otras lenguas naturales, no existe en español. Para expresar este significado, por tanto, debemos recurrir a la paráfrasis. El ejercicio 22 trata de que el estudiante reflexione sobre ello:

\section{Imagen 23}

Ejercicio de morfología flexiva que ayuda a reflexionar sobre los valores de la persona gramatical

\section{Ejercicio 22.}

Considere la siguiente reflexión sobre la primera persona del plural. ¿Echas de menos la diferencia inclusivo/exclusivo en nuestro sistema gramatical? ¿De qué modo evitas la ambigüedad?

Fuente: elaboración propia 


\section{Conclusiones}

En este trabajo hemos presentado 22 ejercicios con los que afrontar la gramática en secundaria de forma distinta. El objetivo en esta etapa de enseñanza obligatoria es dotar a los estudiantes del conocimiento técnico necesario para una reflexión metalingüística profunda. Las unidades y procesos morfológicos no han de ser, sin embargo, un objetivo en sí mismos, sino una herramienta con la que responder mejor a preguntas significativas como las siguientes: ¿cómo y por qué creamos nuevas palabras? ¿Cómo las entendemos? ¿Cómo y por qué jugamos con las palabras? ¿Cómo gramaticalizamos los significados?

Los hablantes usamos nuestra competencia morfológica para resolver situaciones de nuestro día a día. La usamos para crear nuevas palabras cuando hemos olvidado el nombre de un determinado objeto, cuando queremos contestar con humor a una situación o cuando necesitamos nombrar una nueva realidad. La usamos también cuando nos encontramos con una palabra derivada que nunca antes habíamos escuchado. Es una herramienta útil para transmitir afectividad a los demás o para sincretizar significados a través de la gramática. Es muy importante que los estudiantes sean conscientes de estas funciones de la morfología y no la vean como un mero pasatiempo escolástico. Los procesos morfológicos son significativos porque los usamos para relacionarnos con los demás.

El modo en el que se presentan estos ejercicios es novedoso en el sentido de que parten de juegos de palabras, chistes lingüísticos o materiales reales y se formulan preguntas de reflexión. El uso del humor en el aula conllevará, creemos, un clima adecuado para favorecer el aprendizaje en general y la reflexión metalingüística en particular.

En definitiva, hemos querido mostrar que otra forma de enseñar la morfología es posible. Más inductiva, más reflexiva, más significativa y (¿por qué no?) más divertida. 


\section{Referencias bibliográficas}

Aijon Oliva, M. A. (2020). Talking about 'others': Referential readings and pragmatic functions of non-phoric plural third persons in Spanish media discourse. Lingua 243, 1-18. https://doi.org/10.1016/j.lingua.2020.102906

Ambadiang, T. (1999). La flexión nominal, género y número. En I. Bosque, y V. Demonte (Eds.), Gramática Descriptiva de la Lengua Española, Volumen 3, capítulo 74 (pp. 4843-4913). Madrid: Espasa.

Aranda Gutiérrez, C. (2011). El análisis lingüístico de los nombres de marca del sector de alimentación (Tesis Doctoral, Universidad Autónoma de Madrid).

Bosque, I. (2018). Qué debemos cambiar en la enseñanza de la gramática. ReGrOC, 1, 11-36. https://doi.org/10.5565/rev/regroc.12

Bosque, I., y Á. J. Gallego (2016). La aplicación de la gramática en el aula: recursos didácticos clásicos y modernos para la enseñanza de la gramática. RLA. Revista de lingüística teórica y aplicada, $\quad 54 \quad$ (2), 63-83. https://scielo.conicyt.cl/pdf/rla/v54n2/art_04.pdf

Casado Velarde, M. (1999). Otros procesos morfológicos: acortamientos, formación de siglas y acrónimos. En I. Bosque, y V. Demonte (Eds.), Gramática Descriptiva de la Lengua Española, Volumen 3, capítulo 78 (pp. 5075-5096). Madrid: Espasa.

Fernández-Poncela, A. M. (2019). El proceso emocional: el humor y la risa en la educación. Prospectiva. Revista de Trabajo Social $e \quad$ Intervención Social, 285-315. https://doi.org/10.25100/prts.v0i28.6743

Fernández Solís, J. D. (2003). El sentido del humor como recurso pedagógico: hacia una didáctica de las didácticas. Pulso, 26, 143-157.

https://revistas.cardenalcisneros.es/index.php/PULSO/article/view/36

Fredrickson, B. L. (2004). El poder de los buenos sentimientos. Mente y cerebro, (8), 74-78. https://peplab.web.unc.edu/wpcontent/uploads/sites/18901/2018/11/fredrickson2003amsci_spanish.pd f 
Gil Laforga, I. (2020). El análisis morfológico en el aula. Perspectiva, contenidos y actividades, $\operatorname{ReGrOC,} 2$, 43-66. https://raco.cat/index.php/regroc/article/view/363343 [Consulta: 30-092021].

Martín García, J., y Varela, S. (2012). La relevancia de la diacronía para la teoría morfológica. En M. Campos Souto [et al.] (Eds.) «Assi como es de suso dicho». Estudios de morfología y léxico en homenaje a Jesús Pena (pp. 323-336). San Millán de la Cogolla: Cilengua (Grupo USC FILGA).

Pena, J. (1999). Partes de la morfología. Las unidades del análisis morfológico. En I. Bosque, y V. Demonte (eds.) Gramática Descriptiva de la Lengua Española, Volumen 3, capítulo 66 (pp. $4305-$ 4366). Madrid: Espasa.

Santiago Lacuesta, R., y E. Bustos Gisbert (1999). La derivación nominal. En I. Bosque, y V. Demonte (eds.) Gramática Descriptiva de la Lengua Española, Volumen 3, capítulo 69 (pp. 45054594). Madrid: Espasa.

Val Álvaro, J. F. (1999). La composición. En I. Bosque y V. Demonte (eds.) Gramática Descriptiva de la Lengua Española, Volumen 3, capítulo 73 (pp. 4757-4841). Madrid: Espasa.

Varela, S. (1992). Verbal and adjectival participles in Spanish. In Theoretical analyses in Romance linguistics. John Benjamins, 219234.

Varela, S., y J. Martín García (1999). La prefijación. En I. Bosque, y V. Demonte (eds.) Gramática Descriptiva de la Lengua Española, Volumen 3, capítulo 76 (pp. 4993-5040). Madrid: Espasa. 